no previous epoch has the country depended more for its preservation on competent and ascertained knowledge, and never have we had with us a larger number of available men skilled in some branch of knowledge and already familiar with the administrative and functional routine through which that can best be applied to national work. Men of affairs, themselves prominent in the ranks of men of science, are neither few in number nor unknown to constituencies. Something has been said in medicine about the exact constitution and responsibilities of the committee which should select suitable candidates for whom seats could be found. It does not matter very much what method of selection is taken so that the right goal is clearly set up, and there are those ready to be true to the test of the time. A very small sum of money-small as sums go to-day-in the hands of a few administrators acquainted with the problems and with the personnel of the scientific world would permit them at once to consult the party Whips and arrange for the candidature of an experimental group such as competent State chiefs would gladly welcome to the House and constituencies live to be thankful they ever sent there.

J. J. RoBinson.

\section{EPIDEMIC INFLUENZA}

THE name "influenza " is of Italian origin, and 1 is derived from the Latin influxio, which signifies a humour or catarrh. Creighton ${ }^{1}$ gives the following account of its introduction into the English language :-

"It was in 1743 that the Italian name "influenza' first came to England, the rumour of a great epidemic, so called, at Rome and elsewhere in Italy having reached London a month or two before the disease itself. The epidemic of 1743 was soon over, and the Italian name forgotten, so that when the same malady became common in I762 someone with a good memory or a turn for history remarked that it resembled 'the disease called influenza' nearly twenty years before. After the epidemic of $x_{782}$ the Italian name came into more general use, and from the beginning of the present century [i.e, r8or] it became at once popular and vague. The great epidemics of it in 1833 and 1847 fixed its associations so closely with catarrh that an 'influenza cold' became an admitted synonym for coryza or any common cold attended with sharp fever." The last-named usage has lingered in common parlance to the present day, and such "running" colds are frequently contagious. The series of epidemics from r889 to 1893 effectually dispelled the idea of the necessary association of epidemic influenza with catarrh.

It has also been customary since 1893 to term "influenza" any brief febrile affection associated with more or less headache and muscular pain. The nature of such attacks is little known, but the majority are certainly not true influenza. Epidemic influenza is a malady which has probably

1 "History of Epidemics in Britain," vol ii., p. 304.

NO. 2556 , VOL. IO2] existed from the earliest times. Creighton traces allusions to it in the medieval Latin writers, and in the sixteenth and seventeenth centuries strange epidemics are recorded from time to time under such names as "new disease," "hot ague," "sweating sickness," and others which seem undoubtedly to have been manifestations of it, and the disease has recurred again and again with an interval of a few years. In the nineteenth century, after an outbreak in 1855 , more than a generation passed with little or no mention of epidemic influenza in this country, when in the early weeks of the winter of 1889 reports began to be published on the reappearance of influenza in Moscow, Petrograd, Berlin, and other foreign capitals. This epidemic wave, like many that preceded it, had an obvious course from Asiatic and European Russia towards Westerm Europe, and eventually reached London, and in January, I89o, had a decided effect upon the bills of mortality of the city. It spread all over England, Scotland, and Ireland, but by the spring: of that year had almost disappeared.

The features of the disease at this time were a sharp and sudden attack of fever, accompanied with headache, pain at the back of the eyes, pains in the limbs, and severe back-ache, with prostration and a general feeling of misery. Catarrhal symptoms were by no means prominent, but in the elderly the disease was frequently complicated by bronchitis, pneumonia, and heart failure, and convalescence was often prolonged. The pronounced back-ache and absence of catarrh at first suggested that the malady might be dengue fever, but it was soon recognised that the epidemic was one of genuine influenza. The disease recurred in I89r, $189 x-92$, and $1893-94$, and then waned and almost disappeared. The worst period was in January, I89I; in the week ending January 23 the death-rate in London rose to 46 per rooo living (a month previously it had been $2 \mathrm{I}^{\circ} 9$ ), and 506 deaths from influenza were registered, as well as a very high mortality from bronchitis and pneumonia.

After a period of quiescence lasting for threeand-twenty years, influenza in epidemic form once more made its appearance towards the middle of the present year. In May and June it ravaged Madrid and other parts of Spain, afterwards attacking the British and German forces on the Western front, and travelling to this country, Holland, and Scandinavia. London experienced a sharp attack in July, and some 1600 deaths are attributed to it. On the whole, however, this outbreak was a mild one, except among the debilitated and the aged. The usual course pursued by the disease was a sudden onset of sharp fever lasting about three days, with headache and muscular pain, but little catarrh, followed by rapid convalescence. By the end of August the epidemic was practically at an end. During the present month another outbreak has occurred and is in progress, and this time the disease is assuming a more serious character, and many deaths from pneumonia and bronchitis complicating it have been reported, particularly 
among young and presumably strong and healthy adults. South Africa and Tangier are also experiencing severe epidemics.

While in previous epidemics the general progress of influenza has been westwards from Asiatic and European Russia, the epidemic this year was first reported in Spain and travelled northward. It is to be noted, however, that the war has fundamentally changed the general direction of European traffic-that from East to West being suspended, while the North and South traffic has been greatly augmented. It has to be remembered, too, that Chinese and other Eastern coolies have furnished Labour battalions behind the lines on the Western front, and it may be quite likely, therefore, that the disease has been imported from the East in this manner.

With regard to the nature of epidemic influenza, it is undoubtedly a fever of a highly infectious or contagious character, and, therefore, caused by some micro-organism. In the epidemic of the 'nineties Pfeiffer discovered a minute bacillus, difficult to grow except on certain specially prepared culture media, and even then yielding only very delicate growths, and unstained by the Gram method of staining. This is the influenza bacillus which has ever since been regarded as the causative microbe of epidemic influenza. In the epidemic of this year, however, Spanish, British, and German investigators have failed to find the influenza bacillus except in quite a minority of cases. The principal bacteriological findings reported are microbes belonging to the coccus class, either Gram-negative or Gram-positive cocci, and in some of the fatal cases streptococci have been present in the blood.

The difference in the bacteriological findings between the 'ninety and the present epidemics suggests that epidemic influenza, so-called, is not a single disease. We have a parallel to this in the case of typhoid and paratyphoid fevers, which in symptoms closely resemble each other, but which are due to distinct microbial agents. There are also certain differences in the symptoms present in different influenza epidemics which point to the same conclusion.

The principal factor influencing the spread of influenza seems to be close aggregation of individuals. It is the crowded office, workshop, barrack, or camp that suffers most from the ravages of influenza. Dilution with plenty of air mitigates the infectious properties, and free ventilation is therefore important. In the July outbreak favourable reports were given of the value of systematic spraying of the air of offices and workshops with an atomiser spray, using some volatile disinfectant, such as bacterol, in largely preventing the spread of infection. Fatigue and debility are always conducing factors to infection, and the young and the old are generally more prone to contract the disease. Whether any drug has really any power to prevent infection is questionable, but in the 'ninety epidemics there was a general impression that systematic daily doses of quinine were of some use.

R. T. HEWlett.

\section{THE SALTERS' INSTITUTE OF INDUS.} TRIAL CHEMISTRY.

THE Salters' Company has during many years given evidence of its interest in the promotion of scientific education and research by the provision of fellowships tenable by post-graduate workers. It has now taken a further very important step in announcing a scheme for the establishment of an institute to be called "The Salters' Institute of Industrial Chemistry." The offices of the institute will be for the present at the Salters' Hall, and the scheme will be administered by a director, who will be selected on the ground of qualifications based on a distinguished academic career in chemistry coupled with extensive technical experience. An Advisory Board composed of representatives of the Salters' Company, the universities, and the Association of British Chemical Manufacturers is also under consideration.

The Company proposes to establish two types of fellowship, for which post-graduate students of British nationality will be eligible whether graduates of a British university or of a university in the United States or elsewhere. There are to be (I) fellowships to enable post-graduate students to continue their studies at an approved university or other institution under the general supervision of the director of the institute, and (2) industrial fellowships to enable suitably equipped chemists to carry on research for any manufacturer under an agreement entered into jointly by the institute, the manufacturer, and the fellow.

It will be observed that the Company does not at present contemplate the erection of any building or the equipment of any laboratory. Its aim is, therefore, somewhat different from that of the founders of such establishments as the DavyFaraday Laboratory attached to the Royal Institution in London, or the Kaiser Wilhelm Institute opened in 1912 near Berlin. The intention is to add to the number of first-rate chemical technologists available for the service of industry in this country, a class of men which at present scarcely exists and is sorely needed. It is hoped to offer such attractions to some of the best students that on completing their university course they will seek to apply their knowledge to manufacture and industry generally, and that employers will recognise promptly the necessity for such assistance so that openings for such men with suitable remuneration will be provided concurrently with the supply. Hitherto almost the only career available for the honours graduate in chemistry has been in connection with the teaching profession. Probably in future such men will be divided into two classes according to their personal predilections, some going to the works, while others will prefer teaching. In both directions the opportunities provided have been insufficient in number and inadequate in remuneration, so that many cases have occurred in which a man with distinct scientific gifts has been forced by circumstances NO. 2556 , VOL. IO2] 